Research Article

\title{
Statistical Comparison of Cloud and Aerosol Vertical Properties between Two Eastern China Regions Based on CloudSat/CALIPSO Data
}

\author{
Yujun Qiu, ${ }^{1}$ Jing Wang, ${ }^{1}$ and Keran Yang ${ }^{2}$ \\ ${ }^{1}$ Key Laboratory of Meteorological Disaster, Ministry of Education (KLME) and Joint International Research Laboratory of \\ Climate and Environment Change (ILCEC) and Collaborative Innovation Center on Forecast and Evaluation of \\ Meteorological Disasters (CIC-FEMD) and Key Laboratory for Aerosol-Cloud-Precipitation of China Meteorological Administration, \\ Nanjing University of Information Science \& Technology, Nanjing 210044, China \\ ${ }^{2}$ Xinping Meteorological Bureau, Yuxi, Yunnan 653499, China
}

Correspondence should be addressed to Yujun Qiu; qyj@nuist.edu.cn

Received 19 September 2016; Revised 19 December 2016; Accepted 26 January 2017; Published 2 March 2017

Academic Editor: Ke Zhang

Copyright (C) 2017 Yujun Qiu et al. This is an open access article distributed under the Creative Commons Attribution License, which permits unrestricted use, distribution, and reproduction in any medium, provided the original work is properly cited.

The relationship between cloud and aerosol properties was investigated over two $4^{\circ} \times 4^{\circ}$ adjacent regions in the south (R1) and in the north (R2) in eastern China. The CloudSat/CALIPSO data were used to extract the cloud and aerosol profiles properties. The mean value of cloud occurrence probability $(\mathrm{COP})$ was the highest in the mixed cloud layer $\left(-40^{\circ} \mathrm{C} \sim 0^{\circ} \mathrm{C}\right)$ and the lowest in the warm cloud layer $\left(>0^{\circ} \mathrm{C}\right)$. The atmospheric humidity was more statistically relevant to COP in the warm cloud layer than aerosol condition. The differences in COP between the two regions in the mixed cloud layer and ice cloud layer $\left(<-40^{\circ} \mathrm{C}\right)$ had good correlations with those in the aerosol extinction coefficient. A radar reflectivity factor greater than $-10 \mathrm{dBZ}$ occurred mainly in warm cloud layers and mixed cloud layers. A high-COP zone appeared in the above- $0^{\circ} \mathrm{C}$ layer with cloud thicknesses of $2-3 \mathrm{~km}$ in both regions and in all the four seasons, but the distribution of the zonal layer in R2 was more continuous than that in R1, which was consistent with the higher aerosol optical thickness in $\mathrm{R} 2$ than in $\mathrm{R} 1$ in the above- $0^{\circ} \mathrm{C}$ layer, indicating a positive correlation between aerosol and cloud probability.

\section{Introduction}

Aerosol and cloud vertical structures directly affect the atmospheric heating rate [1] and exert great influence on atmospheric radiation and circulation [2-6]. Aerosols are known to have great impacts on cloud properties [7-9]. Earlier studies using aircraft and satellite sounding data have shown that, under the condition of sufficient cloud liquid water, increased aerosol concentrations will increase cloud droplet concentrations, decrease cloud droplet sizes, and increase the lifespans of clouds [10-13].

China has experienced rapid economic growth and dramatic urbanization and thus has experienced increased aerosol loading [14-16]. For example, frequent heavy aerosol loadings have occurred in the Jing-jin-ji metropolis circle (the northern part of East China, including Beijing, Tianjing, and Northern Hebei province) due to its dense population and industry in this region and surrounding areas [14, 17]. Aerosol loadings in the atmospheric boundary layer in this region reached levels of $10^{3}-10^{4} / \mathrm{cm}^{3}$, with submicron particles dominating the loading [18-22]. Local sources and long-range transport both contributed to the high levels of aerosol concentrations [23-25].

To investigate the impacts of aerosols on cloud distributions and other properties in different atmospheric environments such as aerosol pollution levels and humidity conditions, two adjacent regions in the south and north of East China were selected and compared in terms of the distribution characteristics of clouds of different phases. The northern high-latitude region is adjacent to the Jing-jin-ji metropolis 


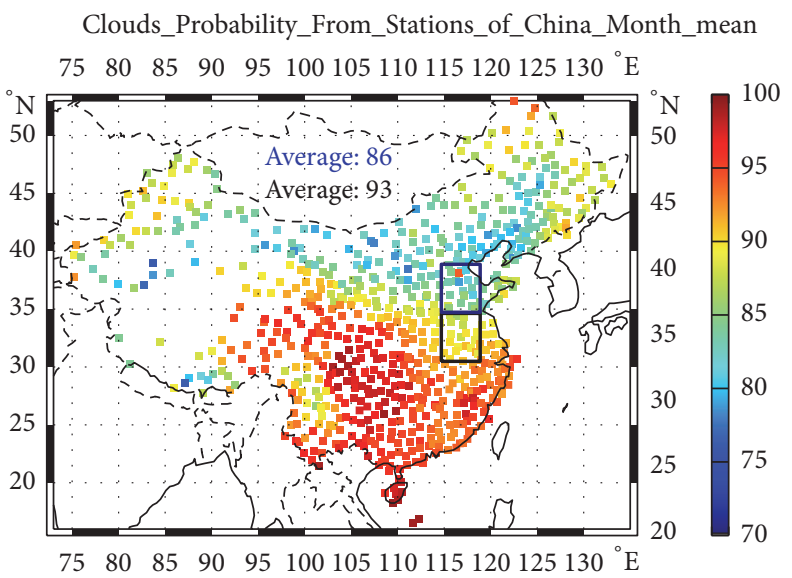

(a)

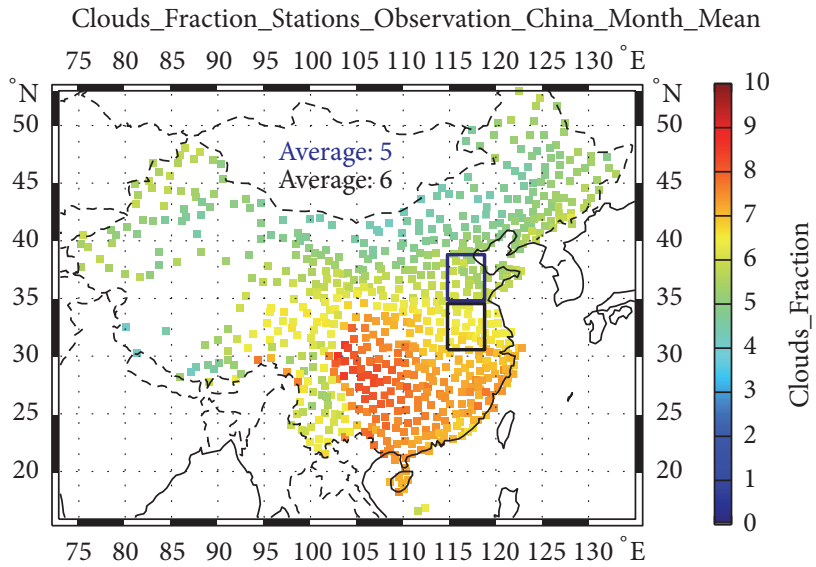

(b)

FIGURE 1: Distributions of monthly mean values of cloud occurrence frequencies and cloud covers observed by the ground observation station. The top rectangular zone represents Region 2 and the bottom one represents Region 1.

circle, and the southern region is located in the Huaihe River drainage area. Aerosol pollution (such as dust and urban pollution aerosols) in the northern region is severer than that in the southern region. Humidity and aerosol conditions in the two regions were first compared. COPs in different cloud layers defined by temperature condition were then compared in four seasons. Finally, the characteristics of COP in different cloud layers were analyzed and discussed under combined humidity and temperature conditions. Research results from the present study are expected to provide the knowledge that is needed for parameterizing cloud formation in climate models.

\section{Data and Methods}

2.1. Data Source. Two regions were selected for comparative research (see Figure 1). Region 1 (R1) is centered at Shouxian County in Anhui Province, and Region 2 (R2) is centered at Tai'an in Shandong province. Both regions are of size $4^{\circ}$ longitude by $4^{\circ}$ latitude. R2 is located just to the south of the JinJing city circle. The observed cloud cover data at the ground weather stations (from the beginning of station observation to 2005; data were obtained from the China Meteorological Administration Resource Center) showed obvious regional characteristics in cloud occurrence frequency and cloud cover fraction in the two regions. From the long-term data, the monthly mean values of cloud occurrence frequency and cloud cover fraction in R1 were, on average, 1.1 and 1.2 times those in R2, respectively, which showed the climate differences of the two regions.

The CloudSat/CALIPSO data (including 2B-GERPROF, 2B-temp, and 2B-lidar) used in the present study covered the period from June 14, 2006, to December 31, 2010. The 2B-GERPROF data contained the radar reflectivity factors of millimeter-wave radar at different altitudes. The temperature data in 2B-temp were obtained from the European Center for Medium-range Weather Forecasts. The 2B-Lidar data were obtained by combining CloudSat and CALIPSO data, including cloud cover and single-layer and multilayer cloud-base and cloud-top heights. Cloud cover data at different heights were used in this study. Data from CloudSat/CALIPSO were obtained by scanning from top to bottom. Data at the lowest levels were believed to have large uncertainties due to the strong reflectivity of the surface leading to anomalously high detection signal. Thus, only data above the $0.5 \mathrm{~km}$ level were used here. Each level (at $0.24 \mathrm{~km}$ increments) scanned by CloudSat was treated as a pixel to obtain statistically the sample size of the pixels within each radar reflectivity factor range, as shown in Figure 2.

Data from the CALIPSO level 2 (CAL_LID_L2 05kmAPro-Prov-V3-01) product for the period from June 13, 2006 , to Sep. 17, 2008, were also used in the present study. This dataset provides aerosol extinction coefficients $(532 \mathrm{~nm}$ and $1064 \mathrm{~nm}$ bands) and cylinder optical thickness.

2.2. Methodology. The 2B-GEOPROF and 2B-GEOPROFLidar data of the CloudSat/CALIPSO product were used to judge the occurrence and positions of clouds. Three criteria needed to be met simultaneously for cloud occurrence: (1) The cloud reflectivity factor is larger than $-40 \mathrm{dBZ}$ and smaller than $50 \mathrm{dBZ}$, which is the $\mathrm{dBZ}$ range of CloudSat cloud radar reflectivity; (2) the CPR cloud mask is larger than 20 and smaller than 40, which is the standard under which CloudSat determines if there is a cloud; and (3) cloud cover is larger than $5 \%$ and smaller than $100 \%$, which reduces the uncertainty of cloud identification and misidentifications such as when aerosols are mistaken as clouds.

The COP at any height was calculated as the ratio of the number of sites with cloud occurrence to the total number of sites scanned in an orbit. The monthly average COP was first obtained for each level before averaging into seasonal values. March, April, and May were treated as spring; June, July, and August as summer; September, October, and November as autumn; and December, January, and February as winter. The COPs and vertical distribution characteristics in the 


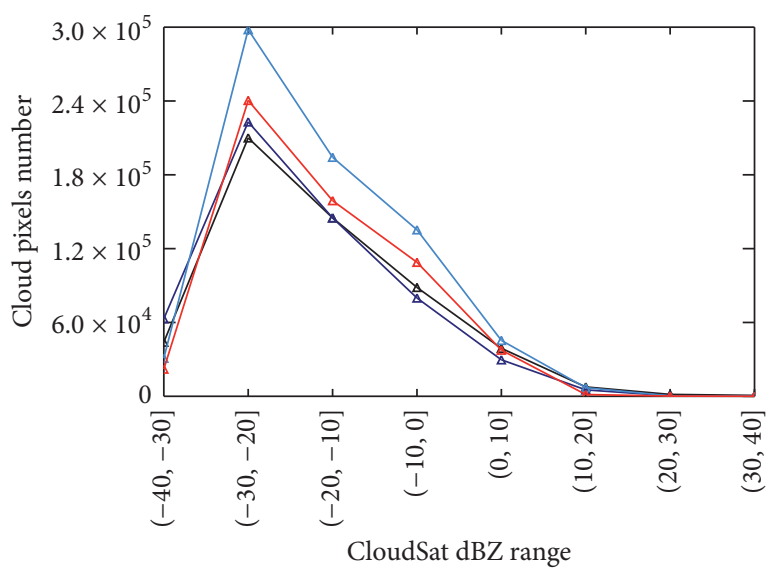

Total cloud pixels:

\begin{tabular}{|c|c|}
\hline$\triangle$ Spring & 536317 \\
\hline Summer & 6226 \\
\hline Autumn & 71132 \\
\hline Winter & 56962 \\
\hline
\end{tabular}

(a)

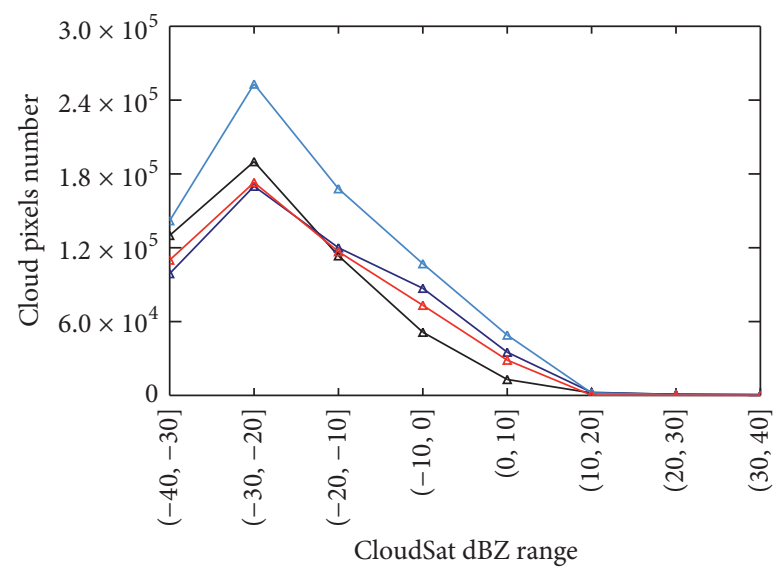

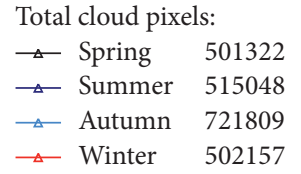

(b)

FIGURE 2: Number of pixels within each radar reflectivity factor range during the four seasons when CloudSat passed through Regions 1 (a) and 2 (b).

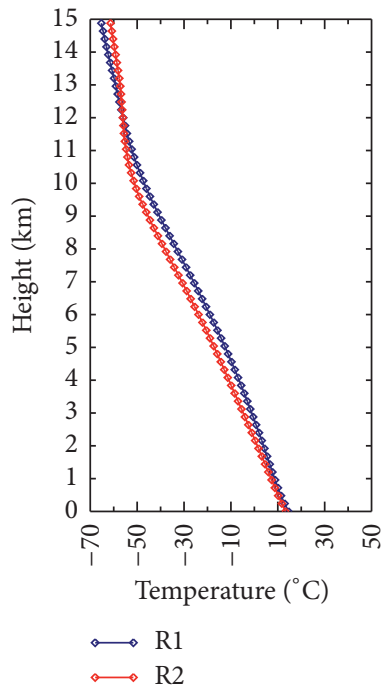

(a)

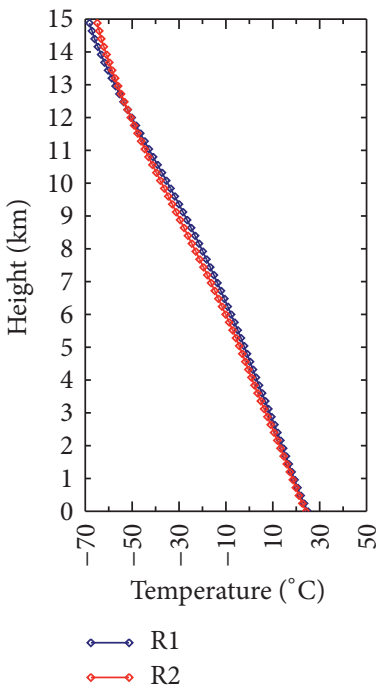

(b)

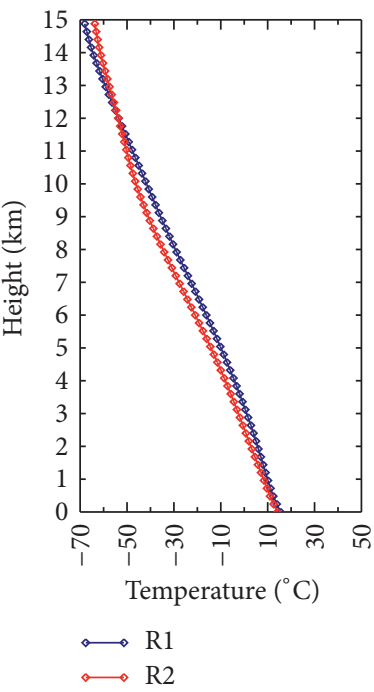

(c)

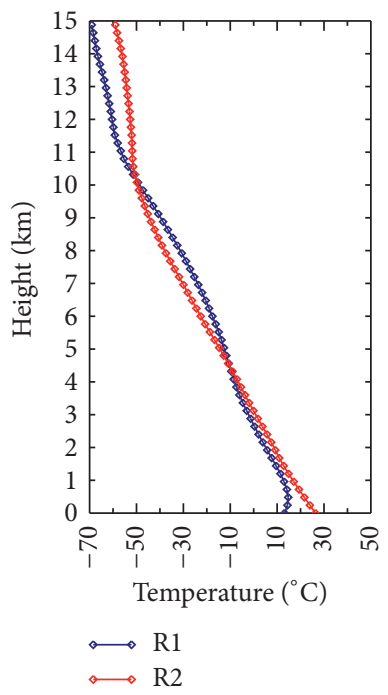

(d)

FIGURE 3: The seasonal temperature profiles in R1 and R2 in (a) spring, (b) summer, (c) autumn, and (d) winter.

two regions and during different seasons were statistically calculated using the nearly five years of data. The COP at any height was obtained by dividing the total number of pixels with cloud occurrence at this height by the total number scanned.

The aerosol extinction coefficient includes both the $532 \mathrm{~nm}$ and $1064 \mathrm{~nm}$ bands. To avoid the influence of certain special weather conditions, only those data with daily mean extinction coefficients larger than 0 for more than two consecutive scanning days were used in the analysis. Seasonal average vertical profiles of extinction coefficients were obtained for the two regions.

\section{Results}

3.1. Atmospheric Environment Differences between R1 and R2. The cloud vertical structure varies greatly with geographical location and time due to many factors, such as the underlying surface conditions and aerosol loading [26-28]. R1 and R2 belong to the monsoon climate zone in East Asia, with higher temperatures in summer and lower ones in winter throughout all vertical levels. The vertical structures of the temperature were similar between the two regions (Figure 3). The difference in temperature was the smallest in summer and biggest in winter. The average temperatures in $\mathrm{R} 1$ in 


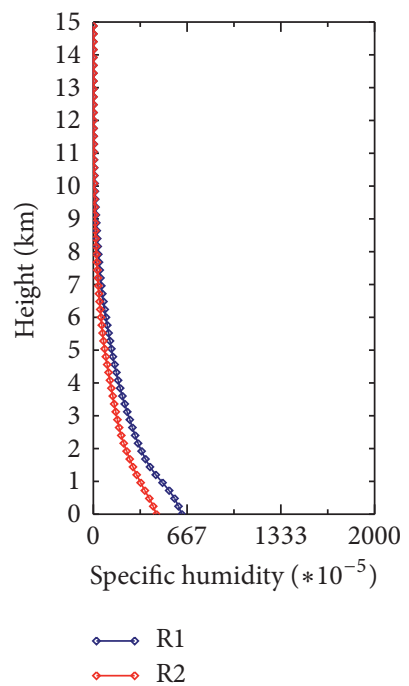

(a)

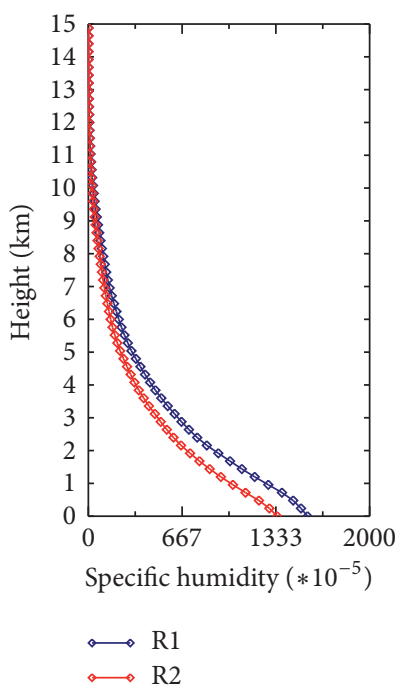

(b)

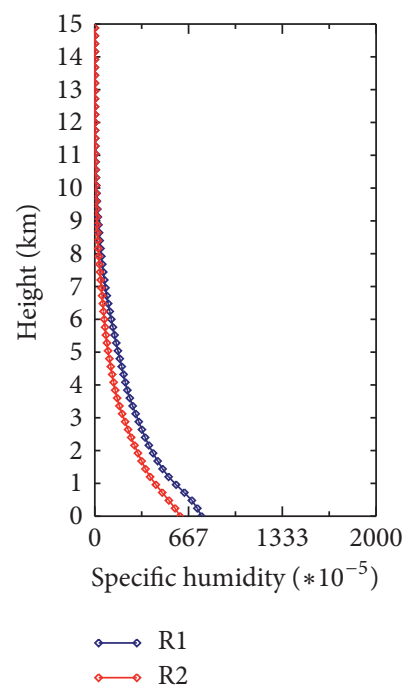

(c)

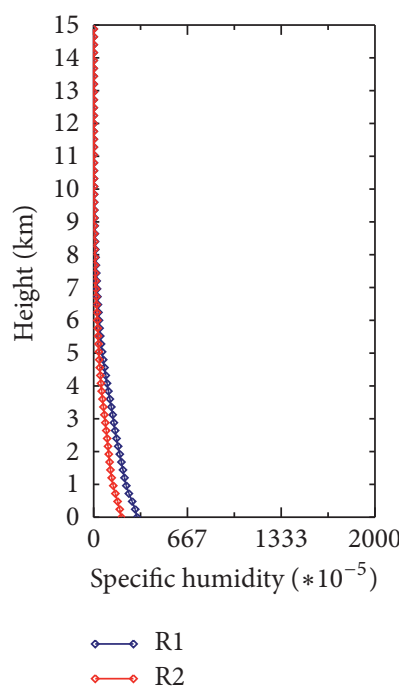

(d)

FIGURE 4: The seasonal profiles of specific humidity in R1 and R2 in (a) spring, (b) summer, (c) autumn, and (d) winter.

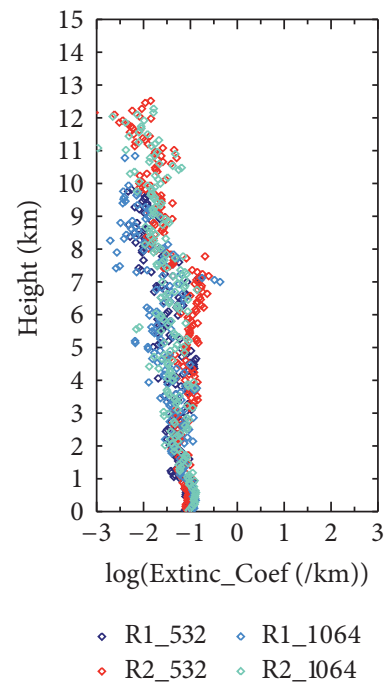

(a)

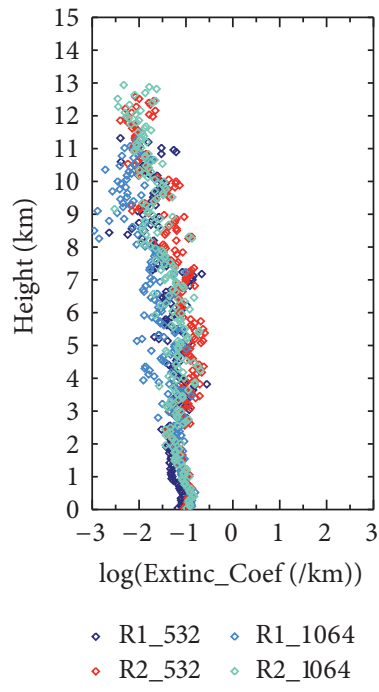

(b)

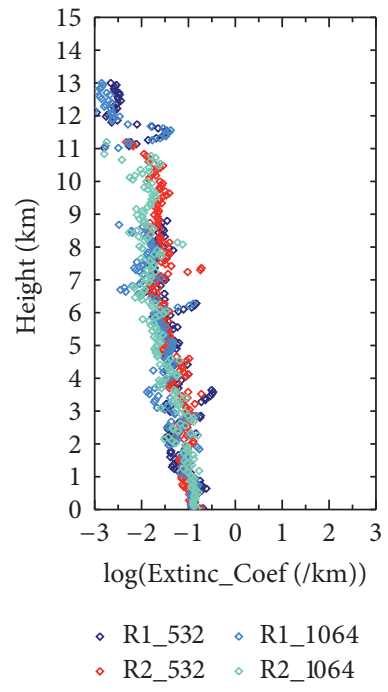

(c)

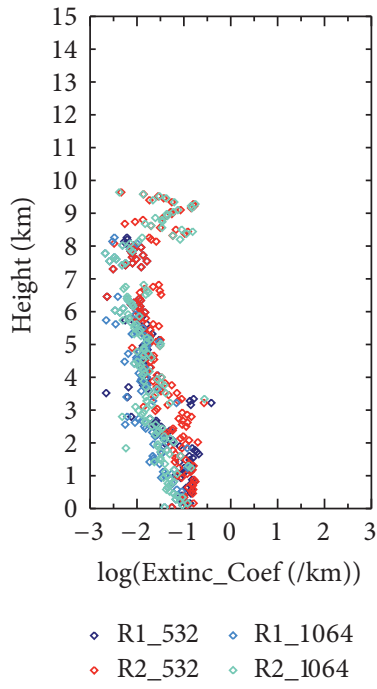

(d)

FiguRE 5: CALIPSO aerosol extinction coefficient vertical profile in (a) spring, (b) summer, (c) autumn, and (d) winter. Shx_532 represents the extinction coefficient of Region 1 at $532 \mathrm{~nm}$ band; Shd_532 represents the extinction coefficient of Region 2 at $532 \mathrm{~nm}$ band; Shx_1064 represents the extinction coefficient of Region 1 at $1064 \mathrm{~nm}$ band; and Shd_1064 represents the extinction coefficient of Region 2 at $1064 \mathrm{~nm}$ band.

spring, summer, and autumn were $2.5,1.2$, and $2.5^{\circ} \mathrm{C}$ higher than those in $\mathrm{R} 2$, respectively. The temperatures below $4.3 \mathrm{~km}$ height in R2 in winter were higher by $0.48^{\circ} \mathrm{C}$ than those in $\mathrm{R} 1$, and the greater temperature differences were close to the ground, which might be due to the impact of winter heating and the Greenhouse Effect of aerosols in R2 [29].

From Figure 4, the average specific humidities in $\mathrm{R} 1$ in spring, summer, autumn, and winter were $1.5,1.3,1.4$, and 1.7 times those in R2, respectively, implying that the water contents in R1 were higher than those in R2.

The aerosol optical depths (AODs) in R2 calculated from the aerosol extinction coefficient profile at the $532 \mathrm{~nm}$ band were approximately 1.9, 2.2, 0.9, and 1.1 times those in R1 in spring, summer, autumn, and winter, respectively (Figure 5) and 1.2, 1.5, 1.1, and 1.7 times the $1064 \mathrm{~nm}$ band. To avoid the influence of the high extinction coefficient of an extreme aerosol pollution event on the mean value of the extinction coefficient, the extinction coefficient was also calculated based on the frequency spectrum of the aerosol extinction coefficient (see Figure 6). The whole extinction coefficient range $\left(0.0-1.5 \mathrm{~km}^{-1}\right)$ was divided into 10 equally sized subranges; for example, the first range is from 0 to $0.125 \mathrm{~km}^{-1}$, and the tenth range is from 1.25 to $1.5 \mathrm{~km}^{-1}$. The average value of the aerosol coefficient in $\mathrm{R} 2$ was larger than 


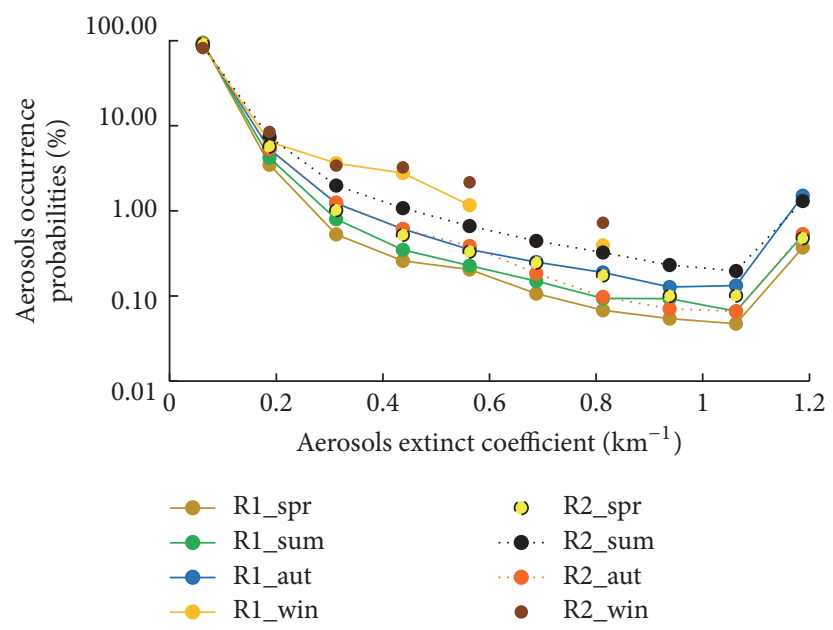

FIGURE 6: The probability of aerosol extinction coefficient at $532 \mathrm{~nm}$ band in the four seasons and two regions.

TABLE 1: The ratio of the COPs, specific humidities, and aerosol extinction coefficients at the $532 \mathrm{~nm}$ band in Regions 1 and 2 in different cloud layers.

\begin{tabular}{|c|c|c|c|c|c|c|c|c|c|c|c|c|}
\hline \multirow{2}{*}{$\mathrm{R} 1 / \mathrm{R} 2$} & \multicolumn{4}{|c|}{$\mathrm{COP}$} & \multicolumn{4}{|c|}{ Specific humidity } & \multicolumn{4}{|c|}{ Extint_532 nm } \\
\hline & Spr & Sum & Aut & Win & Spr & Sum & Aut & Win & Spr & Sum & Aut & Win \\
\hline WCL & 1.5 & 1.1 & 1.3 & 3.8 & 1.3 & 1.2 & 1.2 & 1.8 & 1.2 & 0.8 & 1.2 & 0.9 \\
\hline MCLLT & 1.6 & 0.8 & 1.4 & 1.5 & 1.2 & 1.2 & 1.3 & 1.8 & 0.6 & 0.5 & 1.4 & 1.2 \\
\hline MCLHT & 1.1 & 0.8 & 0.8 & 0.7 & 1.1 & 1.1 & 1.1 & 1.0 & 0.4 & 0.5 & 0.4 & 0.2 \\
\hline ICL & 0.9 & 1.4 & 0.8 & 0.8 & 1.1 & 1.3 & 1.0 & 1.0 & 0.1 & 0.6 & 0.5 & 0.1 \\
\hline
\end{tabular}

that in R1. It is noted that R2 covers Shijiazhuang City and is also adjacent to the south of the Jing-Jin area where aerosol loadings were high. For example, aerosol concentrations in Jing-Jin region in the layers below $4.5 \mathrm{~km}$ were up to $10^{3} \mathrm{~cm}^{-3}$, with average particle sizes from 0.16 to $0.19 \mu \mathrm{m}$ [21]. Aerosol concentrations at the $5 \mathrm{~km}$ layer above Shijiazhuang City were up to $10^{3} \mathrm{~cm}^{-3}$, with average particle sizes from 0.15 to $0.22 \mu \mathrm{m}$ [22]. Aerosol concentrations in Hebei province were up to $10^{3}-10^{4} \mathrm{~cm}^{-3}$ in the layers below $3 \mathrm{~km}$, with average particle sizes of $0.15 \mu \mathrm{m}$ [30].

3.2. COP Vertical Structure. Clouds of different phases have different heating and thermodynamic and radiation processes [31]. Here, the cloud layer with temperatures higher than $0^{\circ} \mathrm{C}$ is referred to as the warm cloud layer (WCL); with temperatures between $-40^{\circ} \mathrm{C}$ and $-20^{\circ} \mathrm{C}$ as the mixed cloud layer (MCL) with lower temperature (MCLLT); with temperatures between $-20^{\circ} \mathrm{C}$ and $0^{\circ} \mathrm{C}$ as the mixed cloud layer with higher temperature (MCLHT); and with temperatures lower than $-40^{\circ} \mathrm{C}$ as the ice cloud layer (ICL). Figure 7 presents the vertical profiles of COP in the two regions during the four seasons. The differences in COPs between R1 and R2 in spring and winter were greater than those in summer and autumn. The COP in R1 in spring was approximately 1.1 times that in $\mathrm{R} 2$. The COPs in R2 in the other seasons were higher than those in R1.

From Figure 7, the COPs within different cloud-phase layers differed significantly. For the COP in the WCL, the average values in $\mathrm{R} 1$ were $0.7 \%, 1.4 \%, 1.0 \%$, and $0.4 \%$ in spring, summer, autumn, and winter, respectively and were $1.5,1.1,1.3$, and 3.8 times, respectively, those in R2. Cloud formation can be influenced by humid conditions and cloud nucleation, which changes the concentration or properties of aerosols. The comparison of the COP results between $\mathrm{R} 1$ and R2 was similar to the comparison of the specific humidity between R1 and R2; in the four seasons; the specific humidities in $\mathrm{R} 1$ were approximately $1.3,1.2,1.2$, and 1.8 times those in R2 in the corresponding seasons (see Table 1). Observations show that the high aerosol concentrations in R2 provided rich condensation nuclei for cloud formation $[17,32]$. The seasonal mean occurrence probabilities of the aerosol extinction coefficients at the $532 \mathrm{~nm}$ band in the range of $1.125-1.25 \mathrm{~km}^{-1}$ in R1 and R2 were compared (see Figure 8). The difference between the aerosol extinction coefficients in R1 and R2 was not similar to that for COP. From Figure 9, the average values of the aerosol extinction coefficient in $\mathrm{R} 2$ in the WCL were approximately 1.2 times those in R1 in both spring and autumn, and the mean extinction coefficients in R2 were approximately 1.3 and 1.1 times those in R1 in summer and winter, respectively. These results implied that water vapor condition may affect COP on the WCL stronger than aerosols.

The COPs in R1 and R2 in the MCL were 70\% and 70.6\%, respectively, which were higher than those in the WCL and ICL. The two regions both reached the highest values of COP in autumn. Compared to the COPs in the WCL, the difference in COPs between the two regions in the MCLLT was larger. The ratio of the COP in $\mathrm{R} 1$ to that in $\mathrm{R} 2$ showed slight 

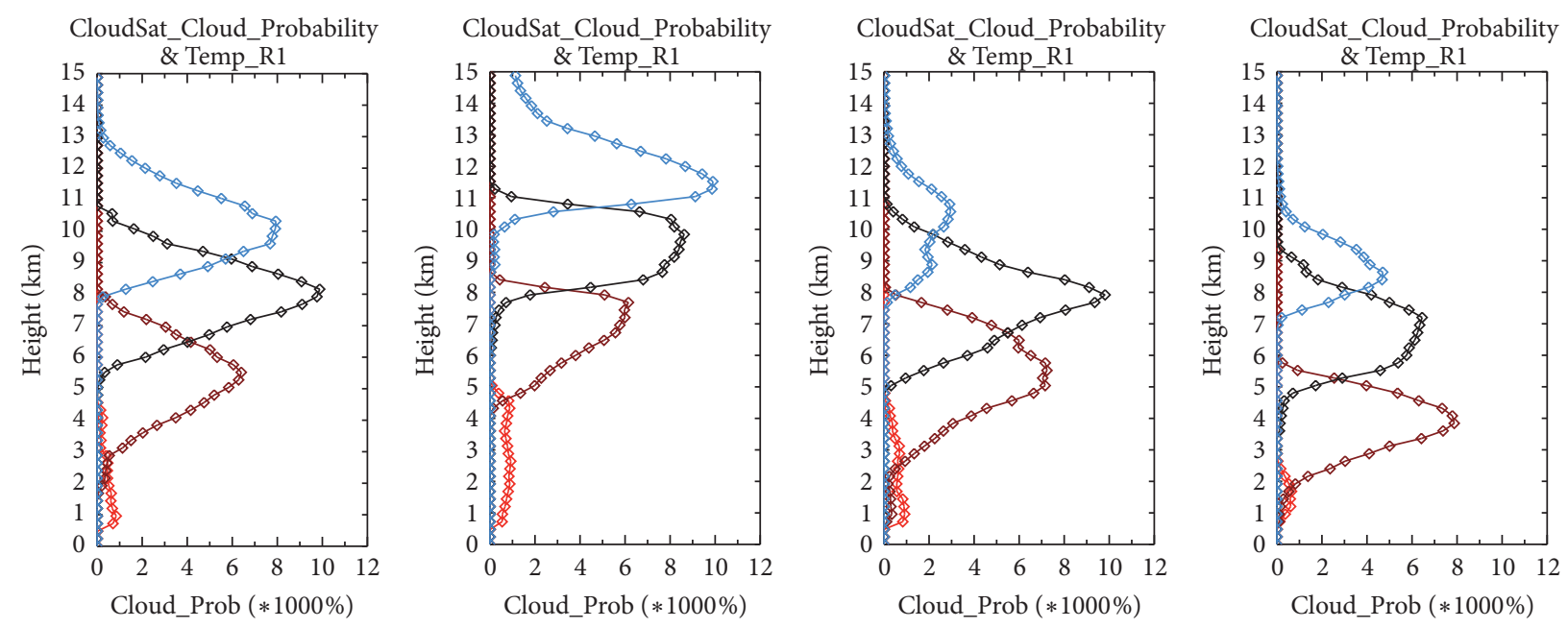

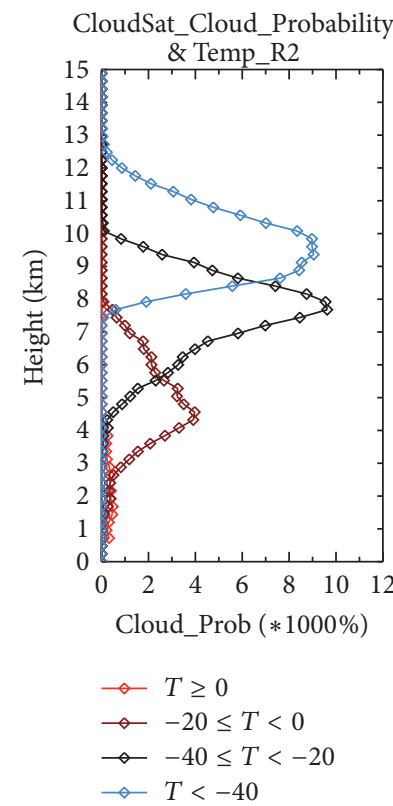

(a)

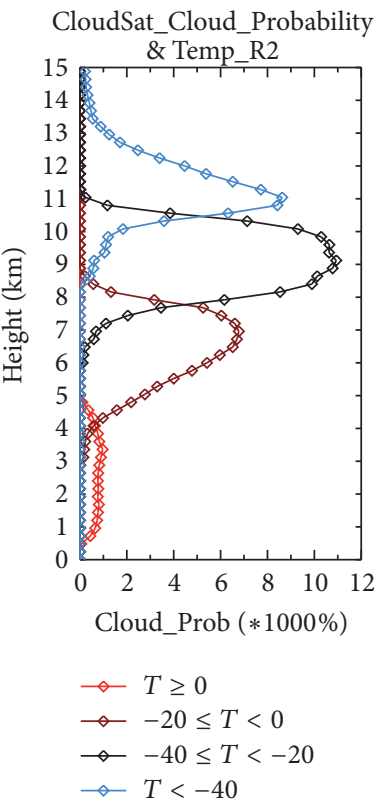

(b)

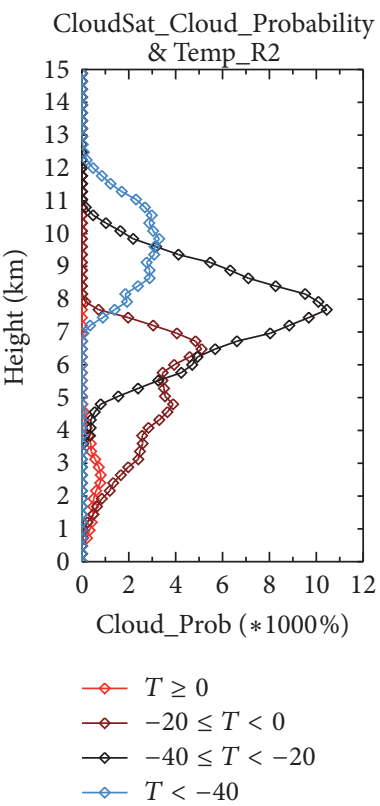

(c)

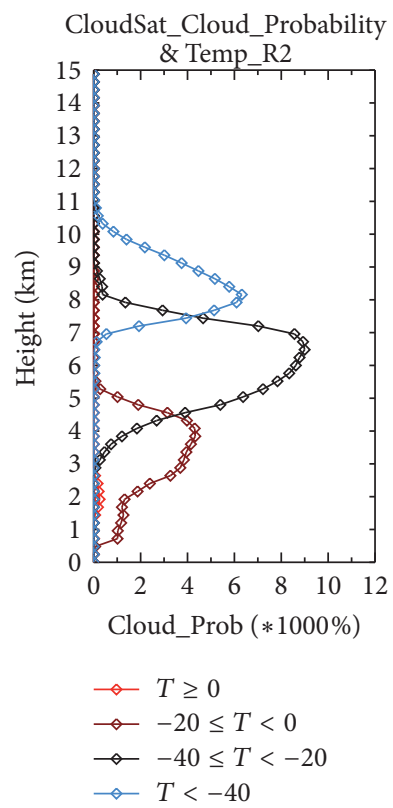

(d)

FIGURE 7: Vertical profiles of COP in R1 and R2 in (a) spring, (b) summer, (c) autumn, and (d) winter, respectively. Red, brown, black, and blue dotted lines refer to the COPs in the warm cloud layer with temperatures higher than $0^{\circ} \mathrm{C}$, mixed cloud layer with temperatures between $-20^{\circ} \mathrm{C}$ and $0^{\circ} \mathrm{C}$, mixed cloud layer with temperatures between $-40^{\circ} \mathrm{C}$ and $-20^{\circ} \mathrm{C}$, and ice cloud layer with temperatures lower than $-40^{\circ} \mathrm{C}$, respectively.

increases in spring and autumn and decreases in summer and winter. The ratio of the COP in $\mathrm{R} 1$ to that in $\mathrm{R} 2$ in winter decreased from 3.8 in the WCL to 1.5 in the MCLLT. The ratio of the specific humidity between R1 and R2 was compared to check the condition of the atmospheric environment. The ratio of the specific humidity in R1 to that in R2 in the MCLLT was similar to that in the WCL in the four seasons. However, the ratio of the extinction coefficient in $\mathrm{R} 1$ to that in $\mathrm{R} 2$ revealed larger differences in summer and winter. The COP in the MCLLT in summer increased to 3.7 times that in the WCL in $\mathrm{R} 1$ and to 5.1 times in R2, which was due to the COP in R2 being higher than that in R1 in the MCLLT. At the same time, the aerosol extinction coefficient in R2 was approximately 2.0 times that in $\mathrm{R} 1$. In addition, the COP in R1 in winter was approximately 1.5 times that in R2 in the MCLLT, and the aerosol extinction coefficient was 1.2 times higher, which implied that the content of aerosols has a positive correlation with cloud occurrence in the MCLLT.

The COPs in R1 and R2 in the MCLHT were higher than those in the MCLLT in all the four seasons. The COPs increased by $3.1 \%, 2.9 \%, 0.8 \%$, and $0.2 \%$ in spring, summer, autumn, and winter, respectively, in R1 and 5.4\%, 4.2\%, 5.8\%, and $5.8 \%$ in R2; the differences were greater in R2 than in $\mathrm{R} 1$. The ratio of specific humidity in $\mathrm{R} 1$ to that in $\mathrm{R} 2$ changed smoothly in the whole troposphere. However, the extinction coefficients in R2 were approximately 2.2, 2.1, 2.5, and 4.2 times those in R1 in the MCLLT, which implied that the aerosols were closely correlated with the COP in the MCLLT. 


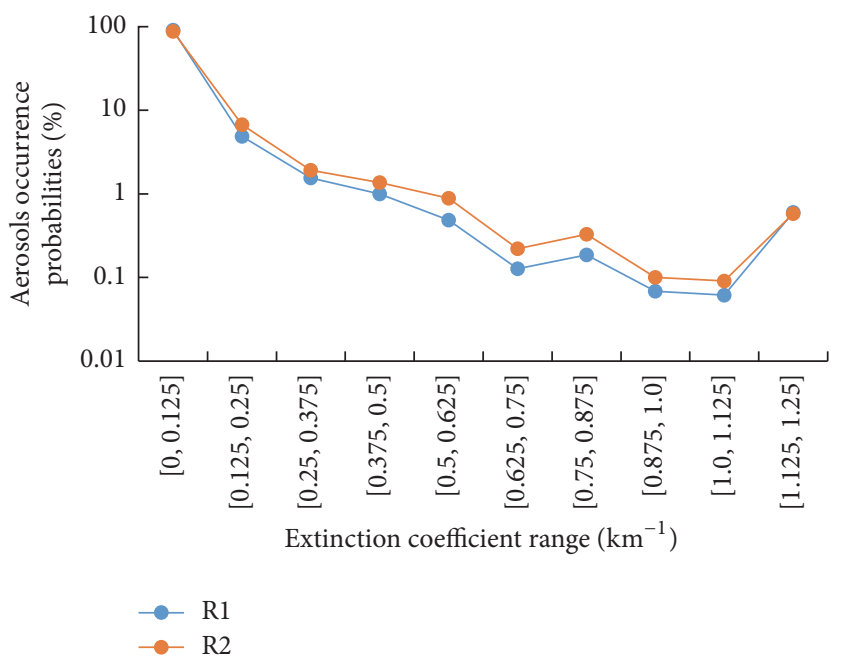

(a)

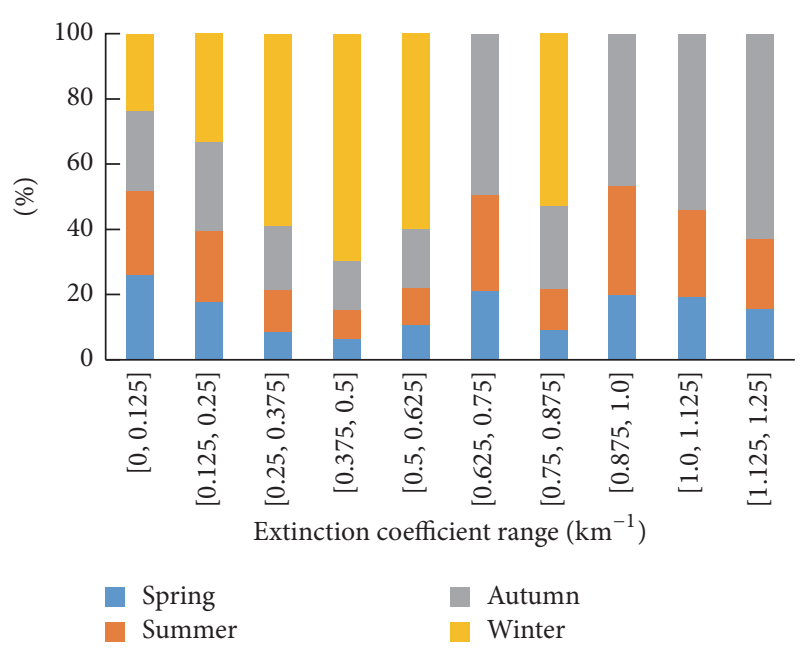

(b)

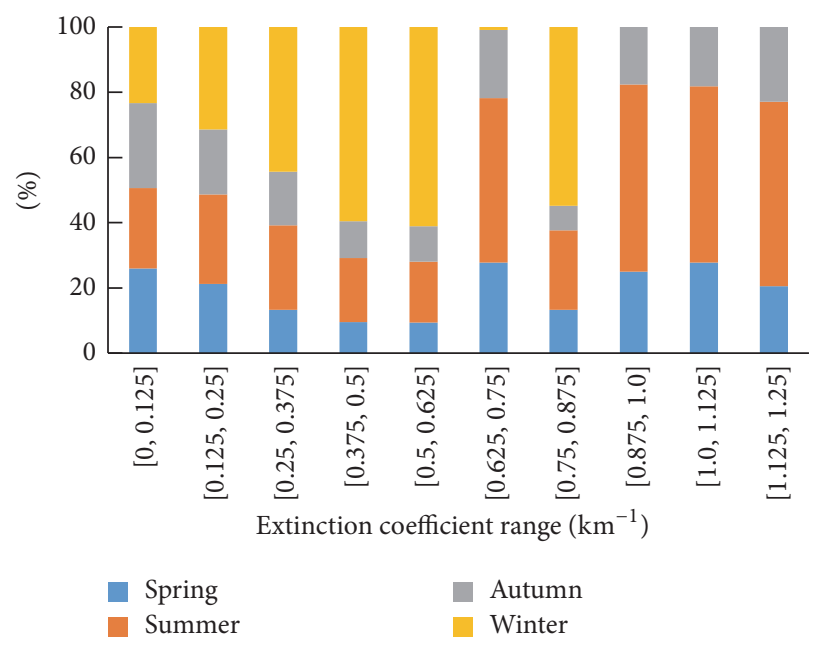

(c)

Figure 8: The mean occurrence probability of aerosol extinction coefficient at $532 \mathrm{~nm}$ band in the range of $1.125-1.25 \mathrm{~km}^{-1}$. (a) Total occurrence probability of aerosol extinction coefficient of four seasons in Region 1 and Region 2. (b) and (c) present that the percent of the occurrence probability in all of the ranges in each season is equal to $100 \%$ in Region 1 and Region 2, respectively. The blue, yellow, gray, and green color represent summer, autumn, winter, and spring, respectively.

The COPs in the ICL were lower than those in the MCL in both of the regions and in all the four seasons. The mean COPs were $26.7 \%$ and $26.8 \%$ in $\mathrm{R} 1$ and $\mathrm{R} 2$, respectively. Except in summer, the COPs in R2 in each season were higher than those in R1. The mean values of the aerosol extinction coefficients at the $532 \mathrm{~nm}$ band in the ICL in R2 were 10.0, 1.7, 2.0 , and 10.0 times greater than those in $\mathrm{R} 1$ in the four seasons. The COP in R2 in spring reached the highest value for all the four seasons, which may be due to the influence of the longdistance transport of dust as ice nuclei from the Taklamakan desert in western China and Inner Mongolia in downwind areas $[24,25]$. Dust in the upwind directions of the two regions and mixed aerosols in the transmission processes may have been incorporated into the troposphere $[25,33]$, which is effected by the East Asian subtropical westerly jet zone [3436]. This process enhanced cloud condensation nuclei in this layer and thus affected cloud distribution characteristics. R2 is closer than R1 to the westerly jet central zone [37].

3.3. Vertical Structure of the Cloud Reflectivity Factor. COP with different radar reflectivities was also investigated here. From the discussion above, the COPs in R1 and R2 mainly appeared in the mixed cloud layers and had good correlations with the aerosol extinction coefficient. Figure 10 shows the vertical profiles of COP within the mixed clouds with cloudbase temperatures higher than $0^{\circ} \mathrm{C}$ and cloud-top temperatures lower than $0^{\circ} \mathrm{C}$ as a function of radar reflectivity in each season.

According to Figure 10, high values of COP were mainly concentrated below $6 \mathrm{~km}$ and in the range of radar reflectivity factors above $-10 \mathrm{dBZ}$ in both of the two regions and during all of the four seasons. The range of the reflectivity 


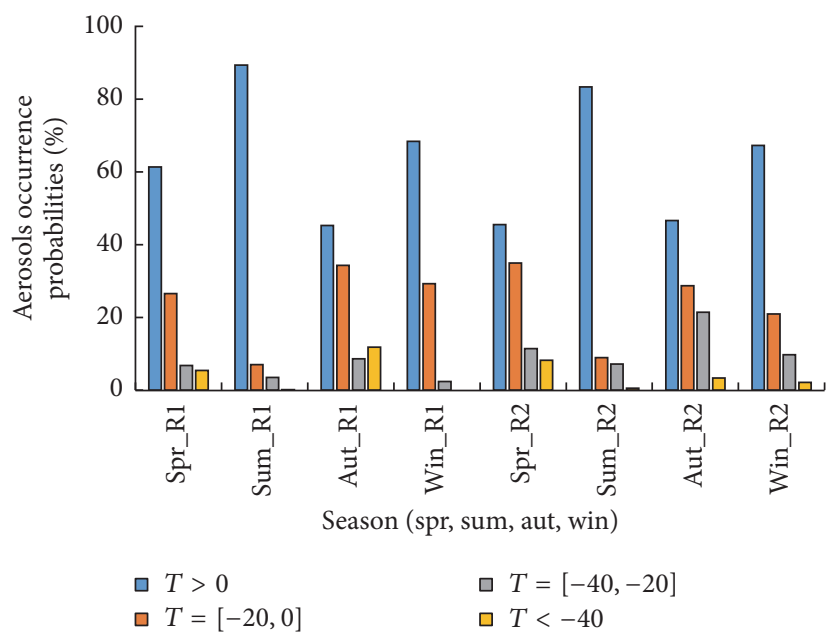

FIGURE 9: CALIPSO aerosol extinction coefficient at $532 \mathrm{~nm}$ band in R1 and R2 in the four seasons. Spr_R1, Sum_R1, Aut_R1, and Win_R1 represent the extinction coefficient of R1 at $532 \mathrm{~nm}$ band in spring, summer, autumn, and winter, respectively; $T>0, T=[-20,0], T=$ $[-40,-20]$, and $T<-40^{\circ} \mathrm{C}$ represent the cloud layers of WCL, MCLLT, MCLHT, and ICL, respectively.
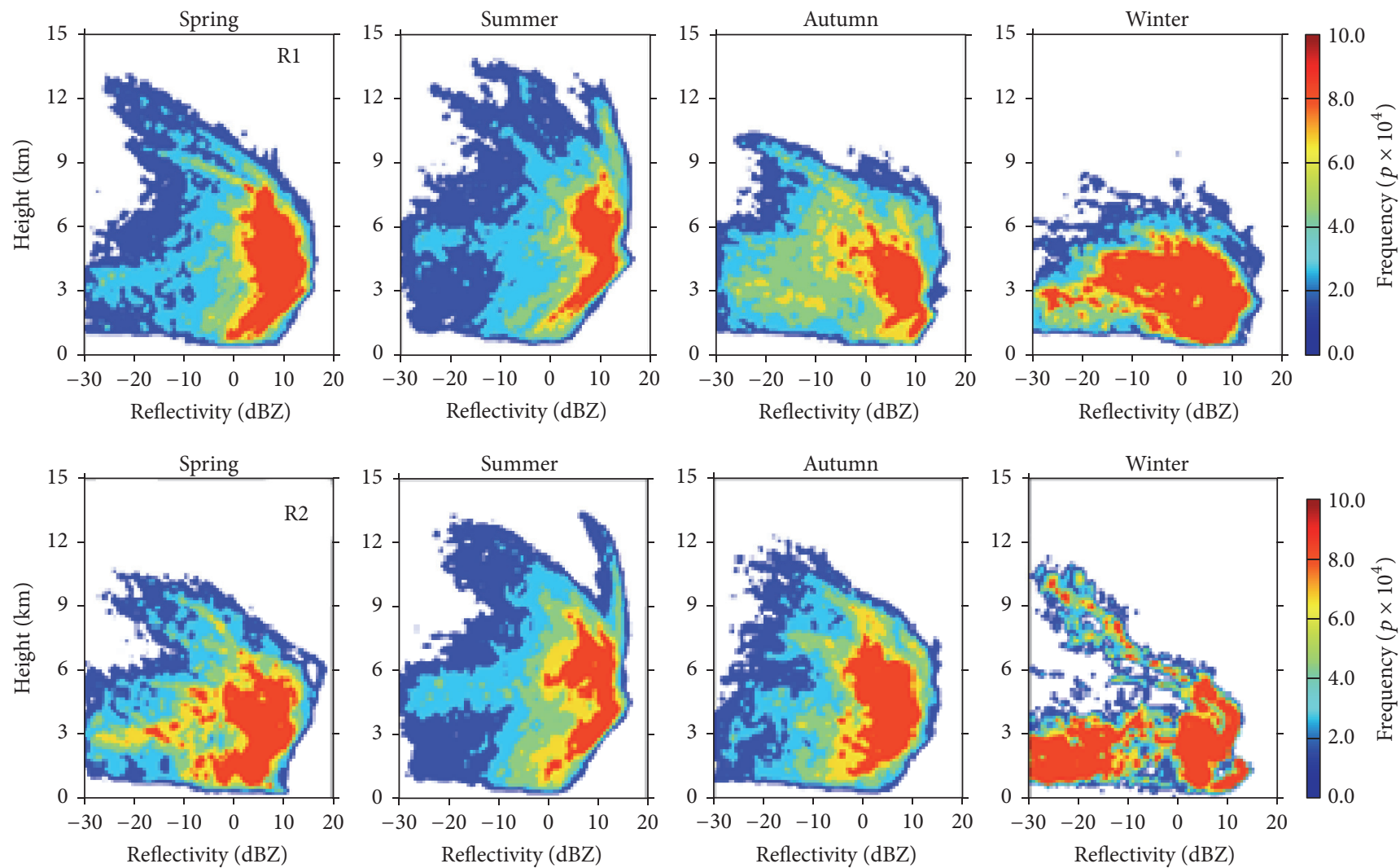

FIGURE 10: COPs of mixed phase clouds in Regions 1 and 2 under different reflectivity factors.

factors with high-COP values (greater than $0.0008 \%$ ) was the narrowest in summer and the widest in winter. Affected by many factors, including temperature and water vapor content, the maximum value of the corresponding radar reflectivity factor decreased with increasing height, and its range became narrower with increasing height. Such trends were more obvious in R2 than R1 during all of the seasons except autumn. In addition, the COP in the layer above $9 \mathrm{~km}$ in summer showed extended high values at approximately $10 \mathrm{dBZ}$ over both regions, which may be due to the influence of strong convective clouds in summer (heap cloud). Tropical convective clouds can be as high as $15 \mathrm{~km}$ [38].

A high-COP layer with a thickness of 2 to $3 \mathrm{~km}$ appeared in the layer above $0^{\circ} \mathrm{C}$, which was determined according 


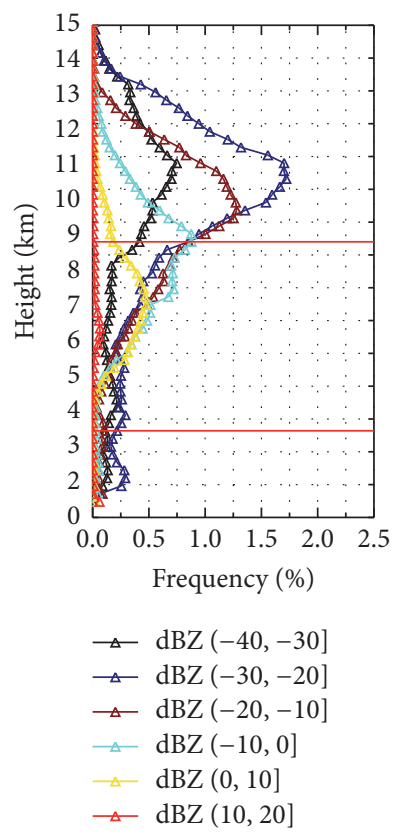

(a)

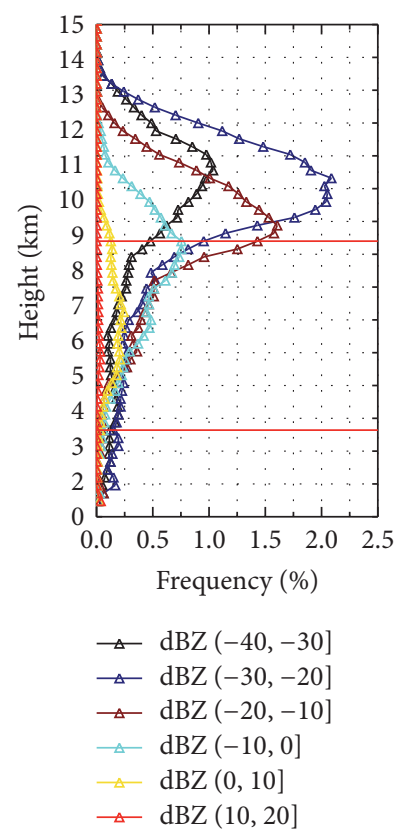

(e)

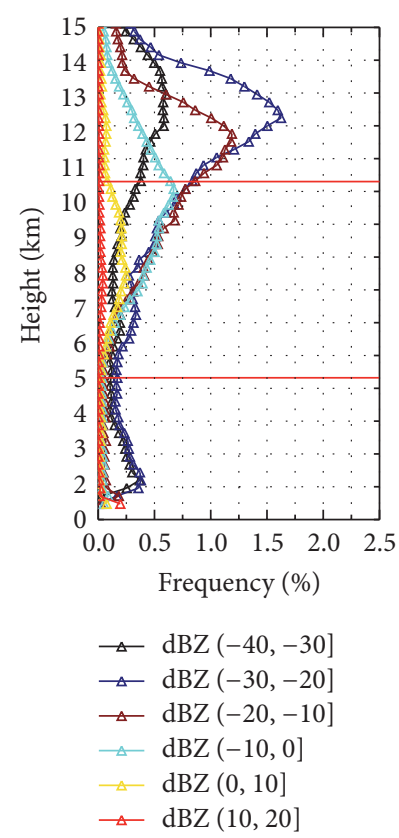

(b)

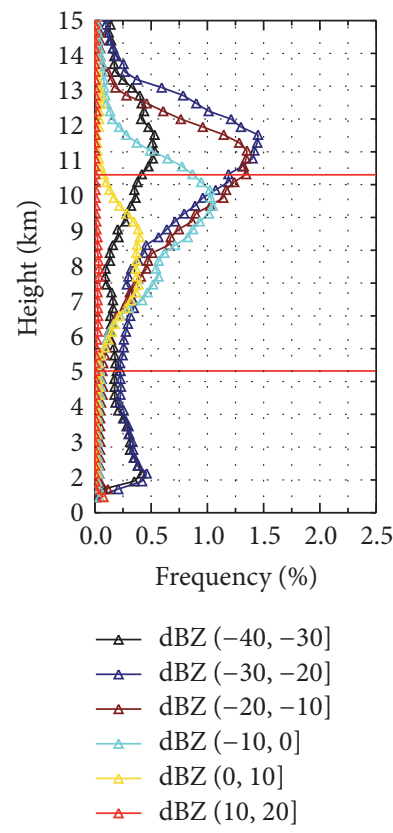

(f)

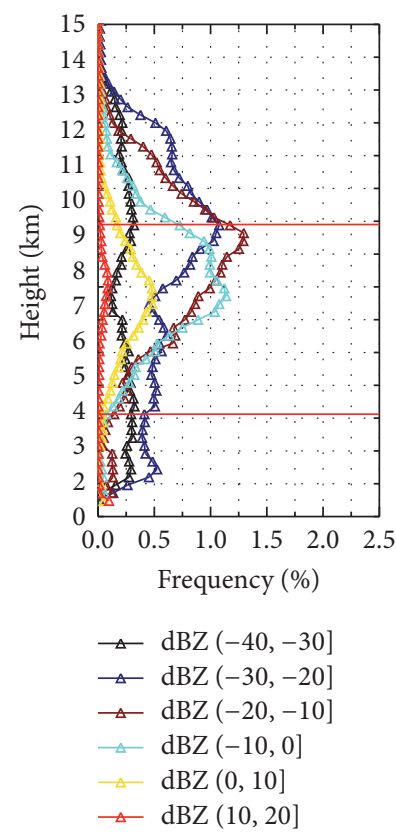

(c)

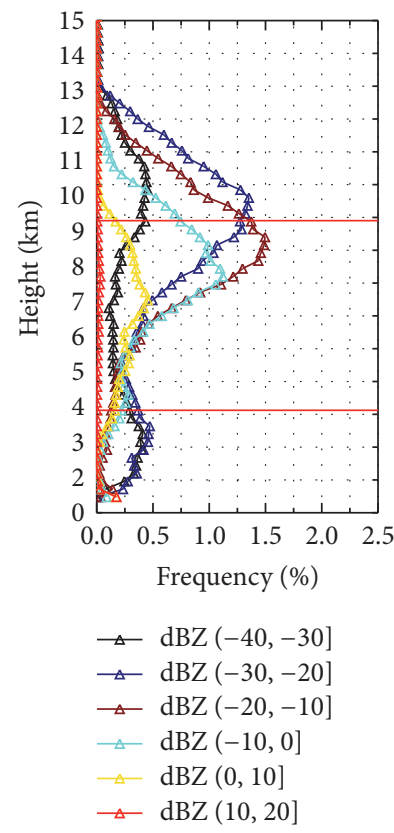

(g)

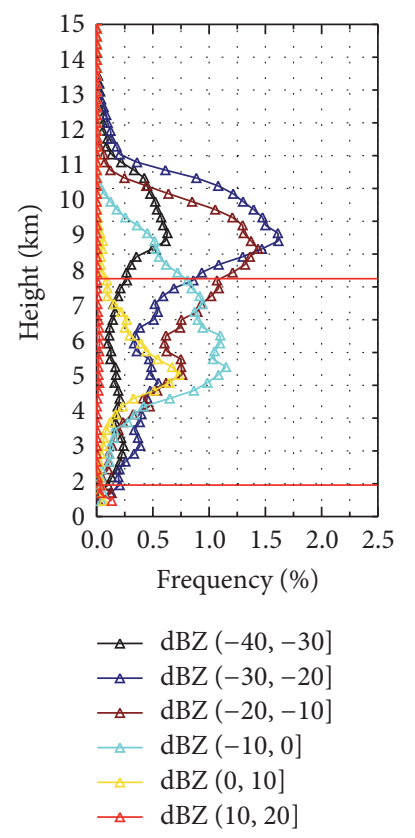

(d)

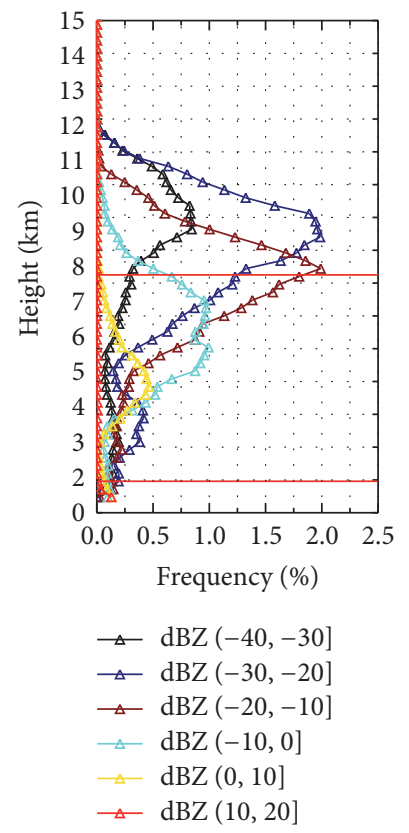

(h)

FIGURE 11: COP in Regions 1 (upper row) and 2 (lower row) within the different ranges of radar reflectivity factor during the four seasons (from left: spring, summer, fall, and winter). The upper and lower horizontal straight red lines represent the $-40^{\circ} \mathrm{C}$ and $0^{\circ} \mathrm{C}$ layer, respectively.

to the temperature in Figure 3, in the $-30 \mathrm{dBZ}$ to $15 \mathrm{dBZ}$ reflectivity factor range over both of the regions and during all the four seasons (See Figure 10). The high-COP values of R2 were more continuous than those of R1 in spring, summer, and winter. Different from that of R1, the COP of $\mathrm{R} 2$ in winter showed a narrow high-value vertical zone with COP value increasing with height, and the corresponding radar reflectivity factor was linearly reduced to $-30 \mathrm{dBZ}$ at approximately $11 \mathrm{~km}$. The range of the corresponding aerosol extinction coefficients in the high-continuous-value zones of COP in the two regions in all the four seasons was also wide according to the data in Figure 5. The aerosol optical thicknesses in $\mathrm{R} 2$ over the $0^{\circ} \mathrm{C}$ layer in the four seasons were $2.5,2.0,1.0$, and 1.0, respectively, for the $532 \mathrm{~nm}$ band and $1.5,2.5,1.3$, and 3.5 for the $1064 \mathrm{~nm}$ band, which were greater than those in R1. The aerosol levels differed greatly between the two regions in spring, summer, and winter. Huang et al. [25] studied the vertical distribution characteristics of 
dust in the Taklamakan desert in the western China Inner Mongolia Gobi sand source area and its downwind direction and determined that $\mathrm{R} 2$ was located in the central area of the downwind zone of the dust. The dust transport from the sand source areas to East China showed a two-layer structure, with the highest dust frequencies appearing at 9 to $11 \mathrm{~km}$ and at $3 \mathrm{~km}$. Even in summer, dust can be transported for long distances [24]. Li et al. [39] showed that large aerosol particles were mainly distributed over the $2.5 \mathrm{~km}$ height in this region, indicating that the dust aerosols from the upwind directions and other types of aerosols mixed in the transportation processes had great influences on the cloud distribution characteristics in R1 and R2. R2 was affected more than $\mathrm{R} 1$ by upwind dust sources.

To further investigate the COPs of clouds of different intensities, Figure 11 shows the vertical profiles of COP within different ranges of the radar reflectivity factor, at an interval factor of $10 \mathrm{dBZ}$, during the four seasons over the two regions. R1 and R2 had similar monsoon climates and thus showed similar seasonal COP distribution characteristics. Clouds in the two regions mainly occurred where the reflectivity factors were less than $-10 \mathrm{dBZ}$, such as in the ICL. The COP in R1 with the reflectivity factor ranging from $-30 \mathrm{dBZ}$ to $-20 \mathrm{dBZ}$ showed a larger value than those in other reflectivity ranges. The percentages of COP were approximately 35.1\%, 35.9\%, $30.8 \%$, and $30.8 \%$ in spring, summer, autumn, and winter, respectively, in $\mathrm{R} 1$ and $37.1 \%, 32.6 \%, 31.1 \%$, and $31.1 \%$ in $\mathrm{R} 2$. The COPs in $\mathrm{R} 1$ in the range of the reflectivity factor larger than $-10 \mathrm{dBZ}$ were $24.1 \%, 22.0 \%, 30.0 \%$, and $30.0 \%$ in spring, summer, autumn, and winter, respectively, in R1 and $18.7 \%$, $26.6 \%, 28.2 \%$, and $28.2 \%$ in $\mathrm{R} 2$. These results showed that the clouds with high reflectivity factors mainly appeared in the MCL and WCL where the water vapor and aerosols were mainly concentrated.

The largest COP in all reflectivity ranges was located at a similar height to where the largest COP in the ICL appeared for all four seasons (Figure 7). The local maxima of the COP appeared in the $-10^{\circ} \mathrm{C}$ to $-15^{\circ} \mathrm{C}$ layer in the two regions in spring and winter, at approximately the $-12^{\circ} \mathrm{C}$ layer in $\mathrm{R} 1$ and the $-15^{\circ} \mathrm{C}$ layer in R2. Zhang et al. [40] also showed that the maximum COP appeared in the mixed cloud layer in the cold season in the Qinghai-Tibet plateau area. Similar results were also found over the East Asia continent [41], which were attributed to favorable ice particle growth process conditions due to sublimation-accretion mechanisms. Through a chamber experiment, Hallett and Mossop [42] observed the occurrence of a large number of secondary ice particles under mixed-layer temperature conditions, and the occurrence probability peaked in the range of $-3^{\circ} \mathrm{C}$ to $-7^{\circ} \mathrm{C}$. These results indicated that the key temperature conditions within the mixed layer increased the occurrence probabilities of the mixed clouds at the corresponding heights.

\section{Conclusions}

The interaction between aerosols and clouds has a complex feedback effect on the changes in aerosol and liquid water content. By investigating the statistical characteristics of cloud and aerosol vertical distributions over two south and north regions in East China, with each region having a size of $4^{\circ}$ latitude by $4^{\circ}$ longitude, stronger correlation was found between water vapor condition and COP than that between aerosol condition and COP in the WCL. The COPs in the mixed cloud layers were approximately $70.0 \%$ and $70.6 \%$ in Regions 1 and 2, respectively, and in the ice cloud layers, $26.7 \%$ and $26.8 \%$. The differences in COP between the two regions in the mixed cloud layer and ice cloud layer were highly correlated with those in the aerosol extinction coefficient.

In addition, the highest cloud proportions in R1 and R2 appeared in the mixed cloud layer in all of the four seasons. High values of COP occurred in a cloud layer of 2 to $3 \mathrm{~km}$ thickness above the $0^{\circ} \mathrm{C}$ layer in all the four seasons. The corresponding reflectivity factors were continuously distributed from $-30 \mathrm{dBZ}$ to $15 \mathrm{dBZ}$. The high values of COP in R2 in this layer were more continuous than those in R1. The clouds with high reflectivity factors mainly appeared in the mixed cloud layers and WCL. The mean values of the aerosol extinction coefficient were higher in $\mathrm{R} 2$ than in $\mathrm{R} 1$ in the layers above the $0^{\circ} \mathrm{C}$ layer in all four seasons, indicating great influences of aerosols on mixed cloud formation.

\section{Competing Interests}

The authors declare that they have no competing interests.

\section{Acknowledgments}

The authors greatly appreciate NASA CloudSat Data Processing Center and China Meteorological Administration for providing data used in the present study. This study was funded by the grant of China Scholarship Council (no. 201608320050), the National Natural Science Foundation of China (Grant no. 41475035), and the Open Funding from the Key Laboratory for Aerosol-Cloud-Precipitation of China Meteorological Administration (Grant no. KDW1102).

\section{References}

[1] G. G. Mace and S. Benson, "The vertical structure of cloud occurrence and radiative forcing at the SGP ARM site as revealed by 8 years of continuous data," Journal of Climate, vol. 21, no. 11, pp. 2591-2610, 2008.

[2] J. Wang and W. B. Rossow, "Effects of cloud vertical structure on atmospheric circulation in the GISS GCM," Journal of Climate, vol. 11, no. 11, pp. 3010-3029, 1998.

[3] B. C. Weare, "Insights into the importance of cloud vertical structure in climate," Geophysical Research Letters, vol. 27, no. 6, pp. 907-910, 2000.

[4] G. L. Stephens, "Cloud feedbacks in the climate system: a critical review," Journal of Climate, vol. 18, no. 2, pp. 237-273, 2005.

[5] P. Knippertz, M. J. Evans, P. R. Field, A. H. Fink, C. Liousse, and J. H. Marsham, "The possible role of local air pollution in climate change in West Africa," Nature Climate Change, vol. 5, no. 9, pp. 815-822, 2015.

[6] J. H. Seinfeld, C. Bretherton, K. S. Carslaw et al., "Improving our fundamental understanding of the role of aerosol-cloud interactions in the climate system," Proceedings of the National 
Academy of Sciences of the United States of America, vol. 113, no. 21, pp. 5781-5790, 2016.

[7] I. Koren, Y. J. Kaufman, D. Rosenfeld, L. A. Remer, and Y. Rudich, "Aerosol invigoration and restructuring of Atlantic convective clouds," Geophysical Research Letters, vol. 32, no. 14, Article ID L14828, 2005.

[8] Z. Li, F. Niu, J. Fan, Y. Liu, D. Rosenfeld, and Y. Ding, "Longterm impacts of aerosols on the vertical development of clouds and precipitation," Nature Geoscience, vol. 4, no. 12, pp. 888-894, 2011.

[9] P. C. S. Devara and M. G. Manoj, "Aerosol-cloud-precipitation interactions: a challenging problem in regional environment and climate research," Particuology, vol. 11, no. 1, pp. 25-33, 2013.

[10] D. Rosenfeld and W. L. Woodley, "Deep convective clouds with sustained supercooled liquid water down to $-37.5 \circ \mathrm{C}$," Nature, vol. 405, no. 6785, pp. 440-442, 2000.

[11] J. Huang, P. Minnis, B. Lin et al., "Possible influences of Asian dust aerosols on cloud properties and radiative forcing observed from MODIS and CERES," Geophysical Research Letters, vol. 33, no. 6, Article ID L06824, 2006.

[12] D. Rosenfeld, U. Lohmann, G. B. Raga et al., "Flood or drought: how do aerosols affect precipitation?" Science, vol. 321, no. 5894, pp. 1309-1313, 2008.

[13] Y. Ma and H. Xue, "A study of aerosol effects on stratocumulus clouds using CloudSat and MODIS data," Beijing Daxue Xuebao (Ziran Kexue Ban)/Acta Scientiarum Naturalium Universitatis Pekinensis, vol. 48, no. 2, pp. 239-245, 2012.

[14] X. Tie and J. Cao, "Aerosol pollution in China: present and future impact on environment," Particuology, vol. 7, no. 6, pp. 426-431, 2009.

[15] Y. Lei, Q. Zhang, K. B. He, and D. G. Streets, "Primary anthropogenic aerosol emission trends for China, 1990-2005," Atmospheric Chemistry and Physics, vol. 11, no. 3, pp. 931-954, 2011.

[16] X. Deng, C. Shi, B. Wu et al., "Analysis of aerosol characteristics and their relationships with meteorological parameters over Anhui province in China," Atmospheric Research, vol. 109-110, pp. 52-63, 2012.

[17] X. Xu, X. Shi, S. Zhang, G. Ding, Q. Miao, and L. Zhou, "Aerosol influence domain of Beijing and peripheral city agglomeration and its climatic effect," Chinese Science Bulletin, vol. 51, no. 16, pp. 2016-2026, 2006.

[18] Y. Fan, X. Guo, D. Fu, and H. Li, "Observational studies on aerosol distribution during August to September in 2004 over Beijing and its surrounding areas," Climatic and Environmental Research, vol. 12, no. 1, pp. 49-62, 2007.

[19] D. G. Zhang, X. L. Guo, and W. Xiao, "Distributive characters of aerosols and cloud droplets in the summer and autumn of 2003 over Beijing and its peripheral areas," Journal of Nanjing Institute of Meteorology, vol. 30, no. 3, pp. 402-410, 2007.

[20] Y. Zhang, Y. Yin, L. X. Shi et al., "An observational study of aerosol property under typical polluted weather condition," Plateau Meteorology, vol. 31, no. 5, pp. 1432-1438, 2012.

[21] G. Lu and X. Guo, "Distribution and origin of aerosol and its transform relationship with CCN derived from the spring multi-aircraft measurements of Beijing Cloud Experiment (BCE)," Chinese Science Bulletin, vol. 57, no. 19, pp. 2460-2469, 2012.

[22] L. C. Ma, Y. Yin, and C. M. Bureau, "Research on airplane observations of atmospheric aerosols over Shijiazhuang area in 2009," Journal of the Meteorological Sciences, vol. 34, no. 1, pp. 47-53, 2014.
[23] Q. Zhang, C. Zhao, X. Tie et al., "Characterizations of aerosols over the Beijing region: a case study of aircraft measurements," Atmospheric Environment, vol. 40, no. 24, pp. 4513-4527, 2006.

[24] J. Huang, P. Minnis, Y. Yi et al., "Summer dust aerosols detected from CALIPSO over the Tibetan Plateau," Geophysical Research Letters, vol. 34, no. 18, Article ID L18805, 2007.

[25] J. Huang, P. Minnis, B. Chen et al., "Long-range transport and vertical structure of Asian dust from CALIPSO and surface measurements during PACDEX," Journal of Geophysical Research Atmospheres, vol. 113, no. 23, Article ID D23212, 2008.

[26] K. Sassen, Z. Wang, and D. Liu, "Global distribution of cirrus clouds from CloudSat/cloud-aerosol lidar and infrared pathfinder satellite observations (CALIPSO) measurements," Journal of Geophysical Research Atmospheres, vol. 114, no. D8, 2009.

[27] J. Huo and D. Lu, "Physical properties of high-level cloud over land and ocean from CloudSat-CALIPSO data," Journal of Climate, vol. 27, pp. 8966-8978, 2014.

[28] J. Peng, H. Zhang, and Z. Li, “Temporal and spatial variations of global deep cloud systems based on CloudSat and CALIPSO satellite observations," Advances in Atmospheric Sciences, vol. 31, no. 3, pp. 593-603, 2014.

[29] N. Sheng and U. W. Tang, "The first official city ranking by air quality in China-a review and analysis," Cities, vol. 51, pp. 139149, 2016.

[30] D. G. Zhang, X. L. Guo, D. L. Gong, and Z. Y. Yao, “The observational results of the clouds microphysical structure based on the data obtained by 23 sorties between 1989 and 2008 in Shandong Province," Acta Meteorologica Sinica, vol. 69, no. 1, pp. 195-207, 2011.

[31] Z. T. Gu, Cloud Precipitation Physics, Science Press, Beijing, China, 1980.

[32] X. H. Shi, "Progress in the study of regional impact of aerosol and related features of heavy fog in Beijing City," Chinese Journal of Geophysics, vol. 55, pp. 3230-3239, 2012.

[33] A. Shimizu, N. Sugimoto, I. Matsui et al., "Continuous observations of Asian dust and other aerosols by polarization lidars in China and Japan during ACE-Asia," Journal of Geophysical Research D: Atmospheres, vol. 109, no. 19, pp. D19-S17, 2004.

[34] X. Y. Zhang, R. Arimoto, and Z. S. An, "Dust emission from Chinese desert sources linked to variations in atmospheric circulation," Journal of Geophysical Research Atmospheres, vol. 102, no. 23, pp. 28041-28047, 1997.

[35] Y. Du, Y. Zhang, and Z. Xie, "Location variation of the East Asia subtropical westerly jet and its effect on the summer precipitation anomaly over eastern China," Chinese Journal of Atmospheric Sciences, vol. 33, no. 3, pp. 581-592, 2009 (Chinese).

[36] R. Jin, W. Li, B. Zhang et al., "A study of the relationship between East Asia subtropical westerly jet and abnormal Meiyu in the middle-lower reaches of the Yangtze River," Chinese Journal of Atmospheric Sciences, vol. 36, no. 4, pp. 722-732, 2012.

[37] X. Kuang, Y. C. Zhang, and J. Liu, "Relationship between Subtropical Upper-Tropospheric Westerly Jet and East Asian Winter Monsoon," Plateau Meteorology, vol. 27, no. 4, pp. 701$712,2008$.

[38] Y. Luo, R. Zhang, and H. Wang, "Comparing occurrences and vertical structures of hydrometeors between eastern China and the Indian monsoon region using cloudsat/CALIPSO data," Journal of Climate, vol. 22, no. 4, pp. 1052-1064, 2009.

[39] J. X. Li, Y. Yin, P. Li, R. Li, L. J. Jin, and J. Li, "Aircraft measurements of aerosol spetial distribution properties in 
Shanxi Province in summer," China Enironmental Science, vol. 34, no. 8, pp. 1950-1959, 2014.

[40] Y. Zhang, H. Chen, and R. Yu, "Vertical structures and physical properties of the cold-season stratus clouds Downstream of the Tibetan Plateau: differences between daytime and nighttime," Journal of Climate, vol. 27, no. 18, pp. 6857-6876, 2014.

[41] J. F. Yin, D. H. Wang, G. Q. Zhai, and W. Zhien, "A study of cloud vertical profiles from the CloudSat data over the East Asian Continent," Acta Meteorologica Sinica, vol. 71, no. 1, pp. 121-133, 2013.

[42] J. Hallett and S. C. Mossop, "Production of secondary ice particles during the riming process," Nature, vol. 249, no. 5452, pp. 26-28, 1974. 

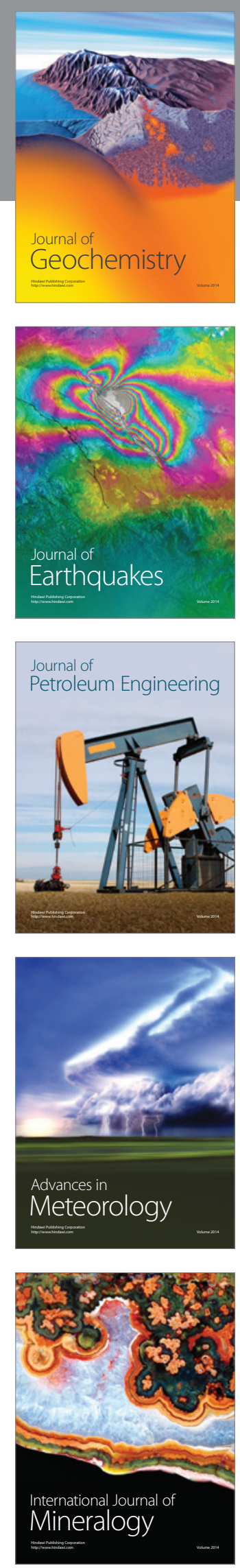
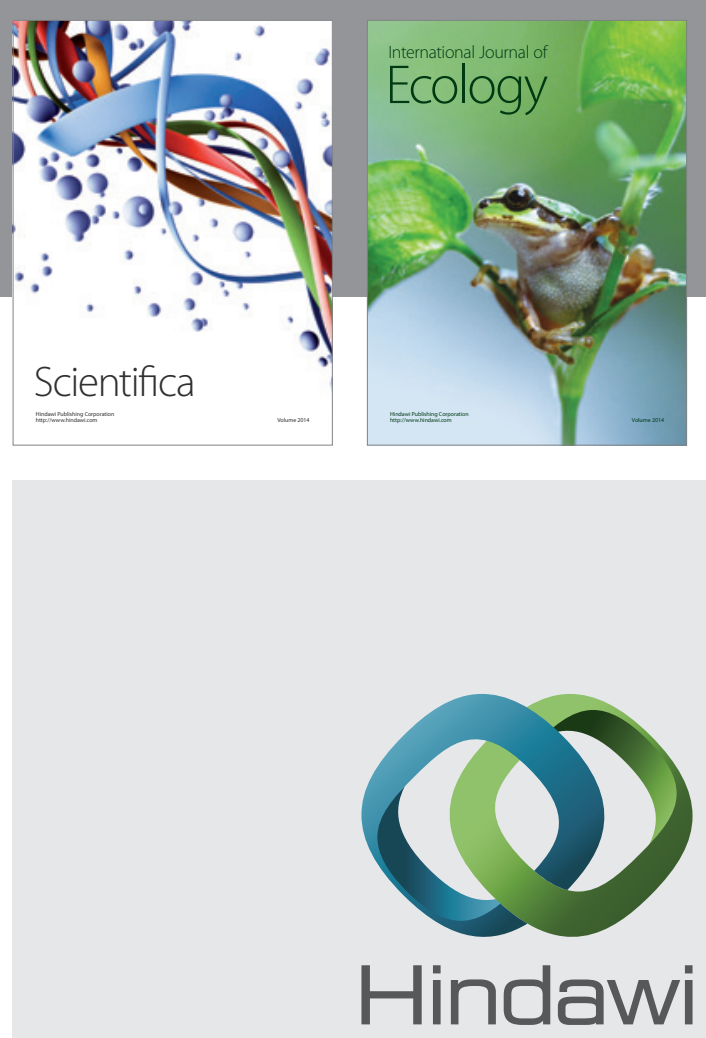

Submit your manuscripts at

https://www.hindawi.com
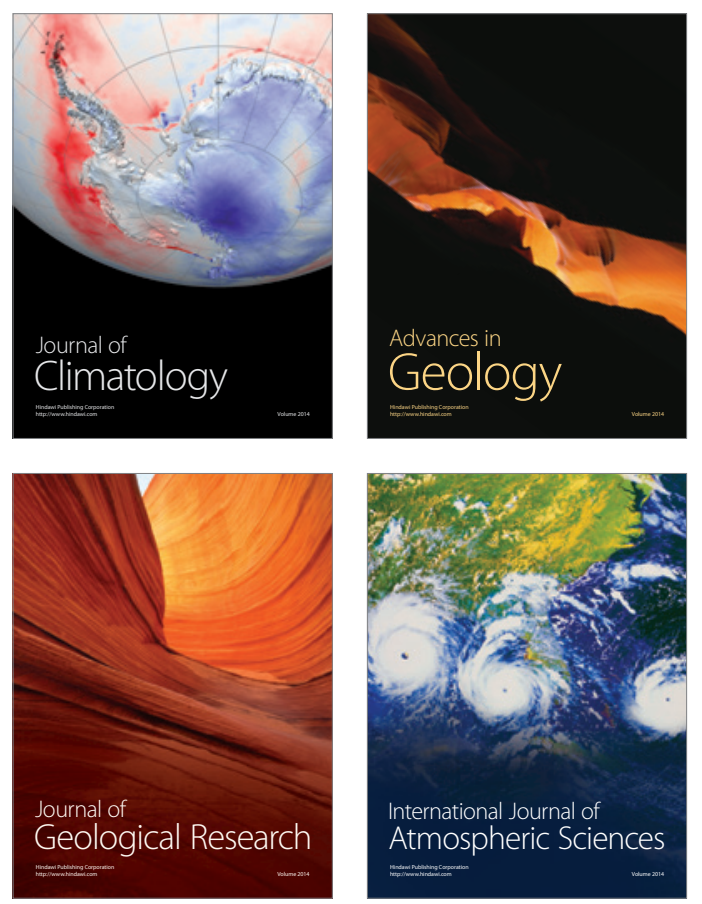

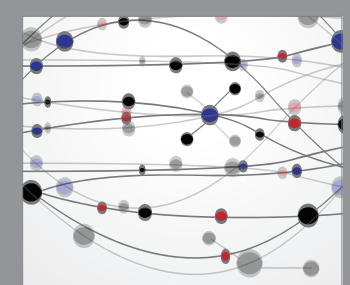

The Scientific

\section{World Journal}
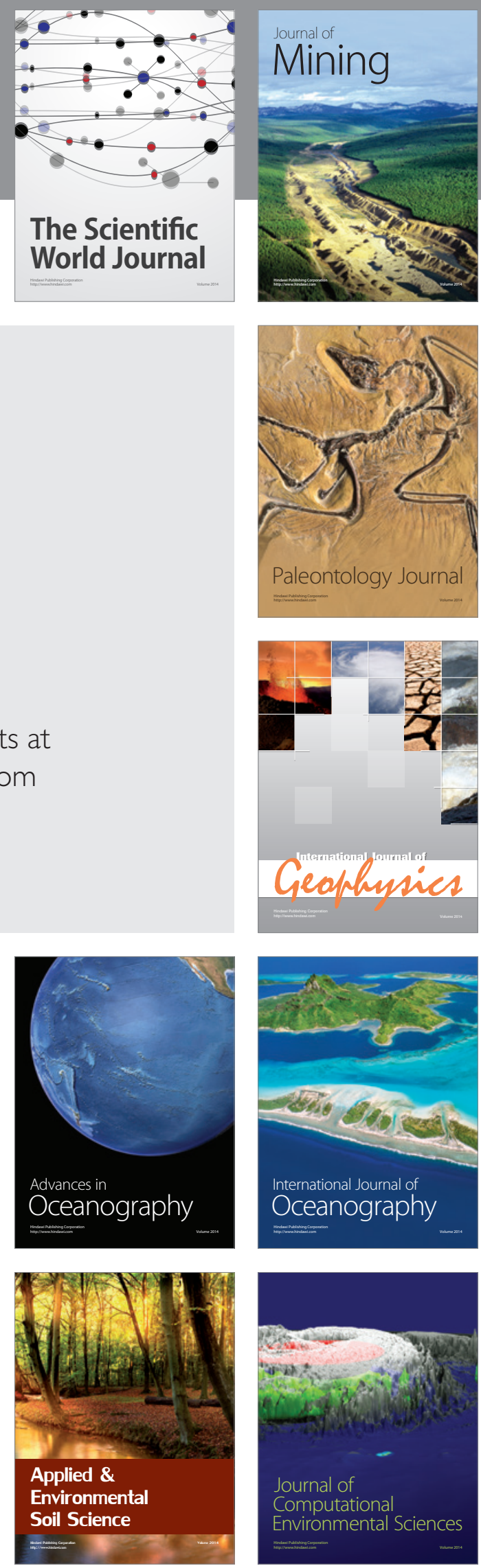